\title{
Towards the design of a Specimen to Investigate Chloride-induced Corrosion Rates in Cracked Concrete Members
}

\author{
Tianhua Deng ${ }^{1, a}$ Arya Chanakya ${ }^{1, b}$ \\ ${ }^{1}$ University College London, Department of Civil, Environmental and Geomatic Engineering \\ WC1E 6BT, London, United Kingdom \\ a ucestde@ucl.ac.uk, bc.arya@ucl.ac.uk
}

Keywords:Chloride, Corrosion, Initiation, Propagation, Steel, Concrete, Crack Width, Crack Distance, Half-Cell Potential Measurement, Galvanic Current Measurement

\begin{abstract}
Many researches have been carried out on the influence of cracks and corrosion rate. There are two conflicting viewpoints on whether the crack width limits are objectively valid to reduce the corrosion rate; One is thatwider crack accelerate corrosion rate, while another opposing opinion is that the crack width does not directly affect the corrosion rate. Thus, the different understanding of the relation of cracks and corrosion reflects on worldwide standards and codes of practice.

According to the majority of existing experimental results, the corrosion rate seems to be independent of cracking width. However, there are no sufficient experimental results for explaining the effect of cracking numbers, cracking distance and other influencing factors on corrosion rate.

In this case, this paper is carried out on the analysis of crack theory and corrosion mechanism to determine their relations in the practical situation. One prospective experimental model is provided by applying Half-cell potential measurement and Galvanic current measurement are established to further explore the relative influencing factors that may affect the corrosion rate.
\end{abstract}

\section{Introduction}

The corrosion procedure can be divided into four stages: corrosion initiation stage, corrosion propagation stage, corrosion- induced crack initiation stage and corrosion-induced crack propagation. Considering the influence of cracks, the time for unacceptable corrosion can be calculated from the begin of the corrosion initiation stage to the end of the propagation stage.

There are two conflicting viewpoints on whether the crack width limit is objectively valid to reduce the corrosion rate. Pettersson and Jorgensen [1] stated that the wider cracks accelerate both the corrosion initiation and propagation. According to their discovery, the concrete corrosion rate with crack width $<0.4 \mathrm{~mm}$ had a significant change. They explained the phenomenon that oxygen is more available to exposed steel on the wider crack. However, an opposite opinion that the crack width does not directly affect the corrosion rate were presented by Arya and Wood [2]; and Beeby [3]. Arya implied that the cracks may affect the corrosion rate at the initiation stage while there was no direct experimental evidence to support the influence of crack on corrosion at propagation stage.

Different viewpoints reflect on many Standards and Codes of Practice. Standard New Zealand [4] suggests the depth of concrete cover is the important factor which can reduce the corrosion and its propagation; Eurocode 2 [5] provides the minimum concrete cover in various corroded environments. American Building Code 318 [6] shows there is no requirement on the width control, except the rules of the bar space and bar cover. However, Chinese Concrete Code [7] regards the crack width might have adverse effects on corrosion rate, since wider cracking is regarded as a more aggressive path. 


\section{Concrete Cracking Width Theory}

Adhesive slip theory and non-adhesive slip theory are excessively regarded on the crack mechanism. Although the average length of the adjacent cracks is thought within the redistributed stress area from $S_{0}$ to $2 S_{0}$, the different definition of $S_{0}$ corresponds to the different width theory.

Adhesive Slip Theory. R. Saligar [8] held that the edge of crack remains as plan. There is no existence of compatibility deformation between concrete and longitude reinforcements. The average length of the adjacent cracks $S_{m}$ and the average width of the cracks $W_{m}$ can be simplified as:

$$
\begin{gathered}
S_{0}=K_{1} \frac{\phi}{\rho} \times \frac{f_{t}}{\tau_{u l t}} \\
W_{m}=2 K_{1} \frac{\phi}{\rho} \frac{f_{t}}{\tau_{u l t}}\left(\xi_{s}-\xi_{c}\right)
\end{gathered}
$$

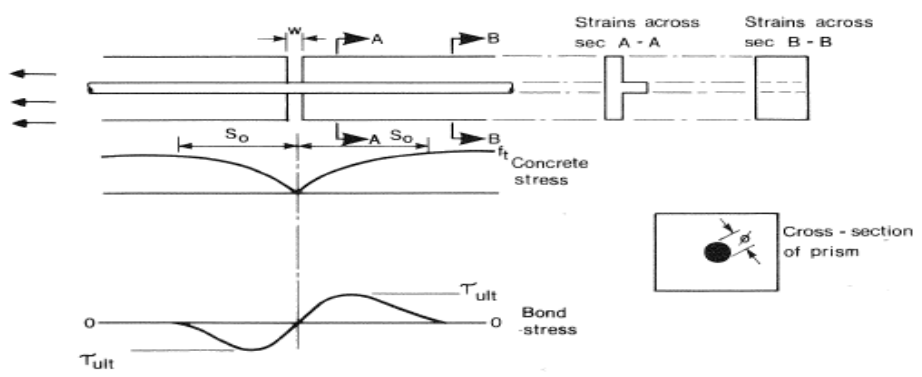

Where and $f_{t}$ represents the ultimate adhesive stress and the adhesive stress.

Figure 1. Adhesive- slip mechanism of cracking conditions near the first crack [3]

Therefore, this can explain the phenomenon for the same amount of reinforcement bar when the steel is thin, the concrete tensile strength is relative low and the lower the adhesive resistance is produced. This means the entire grip needs shorter distance between the nearby cracks to strengthen the adhesive resistance. In this case, the cracks are "thin and close". Otherwise, the cracks generated by the large size of bars are "thick and rare".

Non Adhesive Slip Theory. Broms [9,10] stated that the crack sections are not supposed as the plan. Therefore, the stress on the concrete section is regarded as uneven distribution where the stress at the interface of concrete and reinforcement is larger than the surface. The stress distribution can be thought to correspond with the $45^{\circ}$ engineering rule. Therefore, $S_{m}$ and $W_{m}$ can be regarded as:

$$
\begin{gathered}
S_{0}=C \\
W_{m}=K_{2} C \xi_{S}
\end{gathered}
$$

Where: $C$ is concrete cover depth, $K_{2}$ is experimental data obtained for the tests 


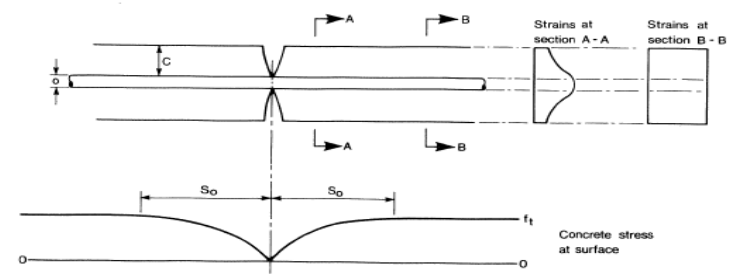

. $\quad$ Figure 2. No adhesive- slip mechanism of cracking conditions near the first crack [3]

\section{Corrosion of Reinforcement}

The corrosion of the reinforcement embedded in the concrete can be regarded as an electrochemical process. During the initiation stage, it signs as the disruption of the oxide on the surface of the steel bar. During the propagation stage, the microcell corrosion is produced in the anodic and cathodic areas.

Initiation Procession. The surface of steel bars is protected with a passive oxide film layer in the highly alkaline concrete condition which can isolate the steel bar from the water. However, the film of steel bar can be destroyed under the carbonation of concrete and the erosion of chlorides.

Carbonation. Carbonation frequently appears in the moisture condition when the atmospheric carbon dioxide penetrates into the concrete. The passive oxide film is damaged by the alkalinity decrease of the concrete from above $\mathrm{PH} 13$ to $\mathrm{PH} 7$.

$$
\mathrm{CO}_{2}+\mathrm{Ca}(\mathrm{OH})_{2} \underset{\left(\mathrm{H}_{2} \mathrm{O}\right)}{\rightarrow} \mathrm{CaCO}_{3}+\mathrm{H}_{2} \mathrm{O}
$$

Chlorides. The principle cause of the corrosion of the steel is the existence of the chlorides in the concrete. This alkaline condition forms the passive oxide film on the embedded steel. However, the propagating chloride ions may be incorporated in the film which prevents the hydroxyl ions on the metal surface. With the decrease of $\mathrm{PH}$ value, the protection of the passive oxide film is broken [12].

$$
\mathrm{Fe}^{2+}+2 \mathrm{Cl}^{-}+4 \mathrm{H}_{2} \mathrm{O} \rightarrow \mathrm{FeCl}_{2} \cdot 4 \mathrm{H}_{2} \mathrm{O}
$$

Propagation Procession. After the disruption of the passive oxide film, the steel is exposed to the $\mathrm{Cl}^{-}$, water and oxygen. Under this condition, the steel corrosion experiences two electrochemistry procedure, located in both anodic and cathodic sites.

The first stage of corrosion occurs at the anodic area; the Fe ions carrying the solution formed by the ferrous ions. The electrons which escape from metal ions react with the dissolved oxygen and the solution to produce the hydroxyl ions forming cathodic area.

Anodic reaction

$$
\mathrm{Fe} \rightarrow \mathrm{Fe}^{2+}+2 e^{-}
$$

Cathodic reaction

$$
0.5 \mathrm{O}_{2}+\mathrm{H}_{2} \mathrm{O}+2 e^{-} \rightarrow 2 \mathrm{OH}^{-}
$$

Secondly, at the cathodic area, with the diffusion of hydroxyl ions and ferrous ions in solution, the electrically neutral reaction occurs at toward place, hence, producing the ferrous hydroxide, which can further react with the oxygen and water to form haematite.

$$
\begin{gathered}
\mathrm{Fe}^{2+}+2 \mathrm{OH}^{-} \rightarrow 2 \mathrm{Fe}(\mathrm{OH})_{2} \\
4 \mathrm{Fe}(\mathrm{OH})_{2}+\mathrm{O}_{2}+2 \mathrm{H}_{2} \mathrm{O} \rightarrow 4 \mathrm{Fe}(\mathrm{OH})_{3}
\end{gathered}
$$




$$
2 \mathrm{Fe}(\mathrm{OH})_{2} \rightarrow 2 \mathrm{H}_{2} \mathrm{O}+\mathrm{Fe}_{2} \mathrm{O}_{3} \cdot \mathrm{H}_{2} \mathrm{O}
$$

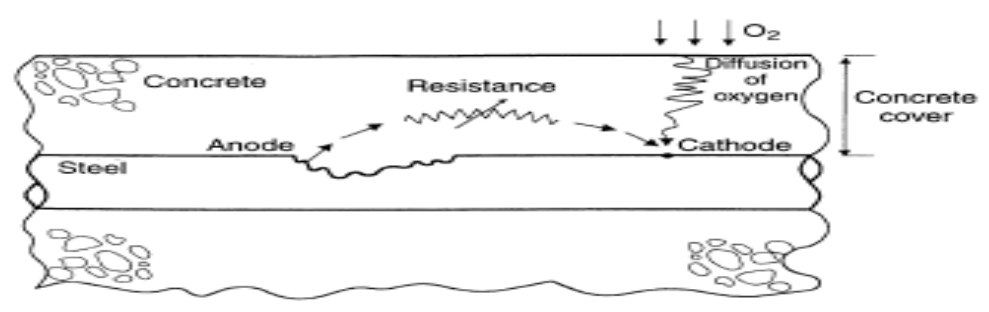

Figure 3. Anodic and cathodic controlled factors on corrosion rate [12]

\section{Experiment One}

Description of Specimens. This experiment targets on an investigation into the influence of the crack frequency, crack width and effective diffusion coefficient of chloride on the corrosion rate. Specimens are designed for ordinary Portland cement, Portland cement mixing ground granulated blast- furnace slag and Portland cement mixing fly ash with two w/b ratio (0.5 and 0.7).

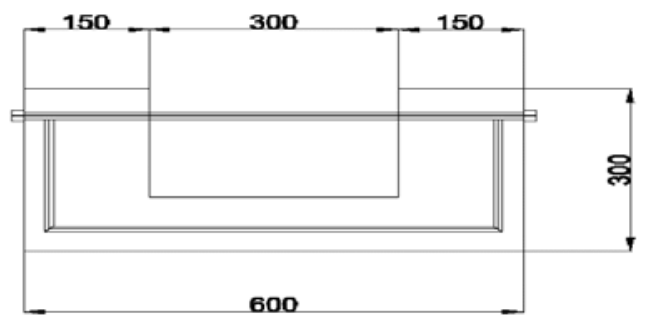

Figure 4. Elevation view of experiment one specimen

A U-shape specimen with a horizontal beam and integral vertical stubs. Two stainless tie bars crossing the stubs are placed on the top of the stubs. The tie stainless bars are not only used for controlling the compressive force to generate the bending in the beam, but also acting as the noble metal for the following galvanic current measurement. In order to determent the integrated influencing factor of cracking numbers, cracking spacing and cracking width, two types of testing steel bar are designed for four $5 \mathrm{~mm}$ diameter bars and one $10 \mathrm{~mm}$ diameter bar. Theoretically, the specimens with different types but the same total section area of the steel bars have the same bending resistance strength, thus the "thin and close" cracks would be produced for the specimen with four $5 \mathrm{~mm}$ diameter bars and "thick and rare" cracks would be generated for the specimen with one $10 \mathrm{~mm}$ diameter bar when the same value of the force is imposed by the adjustment of the tie
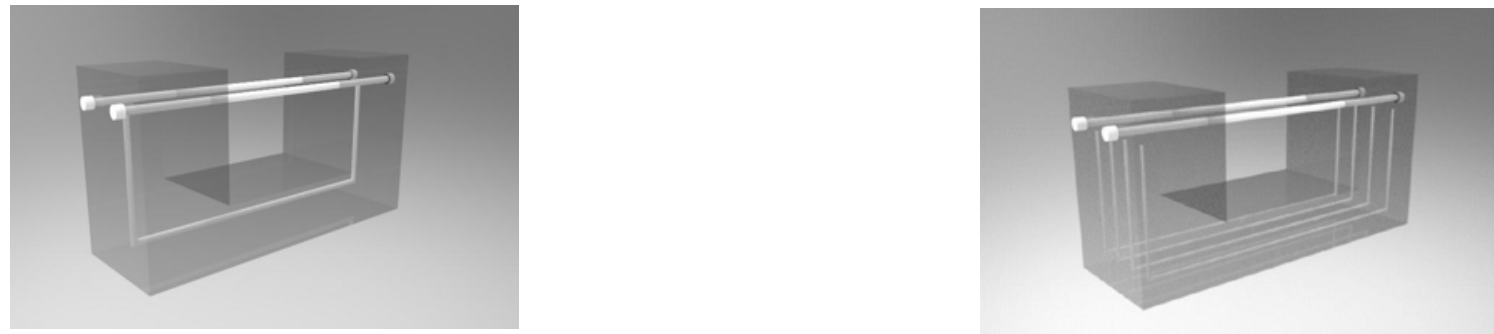

stainless bars.

Figure 5. 3D view of experiment one specimen with one $10 \mathrm{~mm}$ diameter bar and four $5 \mathrm{~mm}$ diameter bars

Experiment programme. There are two stages of experiments are performed in this programme to determine the rate of corrosion initiation (Stage I) and corrosion propagation stage (Stage II).

For Stage I, it is to stimulate the process by chloride ions permeating into the concrete cover and accumulate around the reinforcing steel. Half-cell potential and galvanic current measurements are 
used to detect the corrosion initiation through the half-cell potential to identify the time for starting corrosion of steel in the cracks region. It should be noted that half- cell potential reaching $-350 \mathrm{mV}$ for $\mathrm{Cu}-\mathrm{CuSO}_{4}$ or $-256 \mathrm{mV}$ for $\mathrm{Ag}-\mathrm{AgCl}$ signs the end of stage $\mathrm{I}$.

For Stage II, all the specimens will be removed to chloride induced environment. An external direct current is applied with a current rectifier to accelerate corrosion propagation, thereby the loss weight of corroding reinforcing steel can be measured. Meanwhile, $\mathrm{Cl}^{-}$and $\mathrm{OH}^{-}$concentration is going to be tested during the corrosion propagation stage to understand further the influence of the diffusion of chloride and oxygen on corrosion rate. H.A. Berman [15] held the $\mathrm{Cl}^{-}$concentration can be measured with silver nitrate solution using a chloride ion selective electrode and the $\mathrm{OH}^{-}$ concentration be tested by titrating with $0.1 \mathrm{M}$ hydrochloric acid using phenolphthalein indicator.

Half-Cell Potential Measurement (Stage I).According to ASTM C876-91[16], Cu-CuSO 4 or $\mathrm{Ag}-\mathrm{AgCl}$ can be used as an electrode for half-cell potential measurement and the potential reading should be observed daily during the period of wetting.

Galvanic Current Measurement (Stage I). Galvanic Current Measurement is applied to test the corrosion rate in stage I. The current generated by the electric potential difference between these two types of metal is called galvanic corrosion current, the amount of which can reflect the degree of corrosion activity in the cell. In this experiment, according to measure the voltage of the shuntresistor with a given electric resistance, the galvanic corrosion current can be calculated which must be monitored for daily observation.

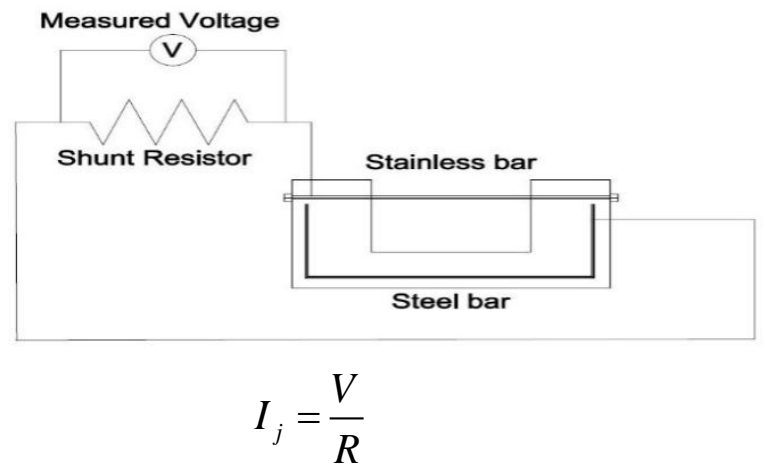

Figure 6. Test for galvanic current measurement

Application of External Current (Stage II).An external direct current is applied to the specimens with a rectifier to accelerate that rate of corrosion propagation (Stage II). The beams with the same binder and w/c ratio can be categorised as one group. Two ends of the rectifier are connected to the steel bar in the specimen and the stainless bar through the shunt resistor, respectively. A voltage is also applied to each specimen. It should be noted that the parameter of 5\% weight loss on the reinforcing steel is regarded as unacceptable damage which can be calculated as:

$$
W_{\text {loss }}=(T C) \frac{E W}{F}=\left\{\sum_{j=1}^{n}\left[\frac{I_{j}+I_{j+1}}{2} \times\left(t_{j}+t_{j+1}\right)\right]\right\} \times \frac{E W}{F}
$$


Where: Total weight loss of reinforcing steel, Total electric charge, Equivalent weight. The Faraday's constant in electric charge, The measured current.

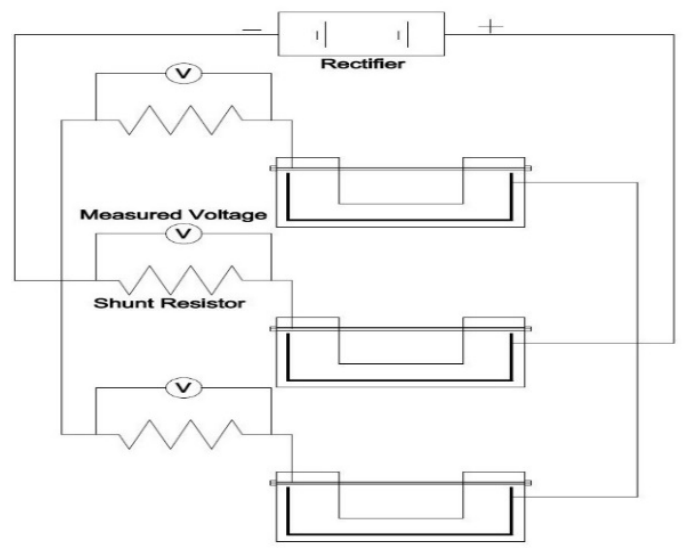

Figure 7.Test for application of external current

\section{Result and Discussion}

The study contributes towards a further understanding of the combined influence of cracking widths, distance, binder type and w/c ratio on the chloride induced corrosion. Some important results can be revealed by following measurement:

- The group of the specimens with the same binder, w/c ratio and different types of reinforcing steel can be selected to analyse the corrosion-induced by the multi-cracks during the initiation and propagation stage.

By comparing specimens of "thin and close" and "thick and rare" cracking by half-cell potential, the influence of cracking width on corrosion initiation stage can be further ascertained.

By measuring the weight of loss reinforcing steel bar of "thin and close" and "thick and rare" specimens, the detailed characteristic of multi-crack specimens can be observed by the weight loss results to determine the effect of the cracking numbers and distance on the corrosion rate during the propagation stage.

- The group of the specimens with the same reinforcing steel, w/c ratio and different binder can be selected to research the material characteristic to the corrosion during the propagation stage.

By measuring the weight of loss reinforcing steel bar of different material specimens by application of external current, it can be observed the performance of the chloride permeability capacity of different types of the cements.

- The group of the specimens with the same binder, type of reinforcing steel and different w/c ratio can be selected to research the influence of the w/c ratio on the corrosion rate during the propagation stage.

Because of the current flow through the specimens added by a rectifier, which increases the electrons to combine with the water and oxygen to generate the hydroxyl ions quicker. Irrespective of the cause, the depassivation caused by the chloride ions do not affect the external current. In this case, the amount of $\mathrm{OH}^{-}$ions are always enough to participate in electrochemical reaction, therefore, the corrosion rate can be regarded on the diffusion rate of the chloride ions. Actually, the deviation of the chloride diffusion between two different w/c ratio concrete specimens as well as its deviation of corrosion propagation period can be explained by the relation between w/c and corrosion rate. 


\section{References}

[1] Pettersson, K. and Jorgensen, O. (1996). The effect of cracks on the reinforcement corrosion in high-performance concrete in a marine environment. Canada: Proceedings of the $3^{\text {rd }}$ ACI/CANMENT International Conference on the Performance of Concrete in the Marine Environment, St Andrews- by-the Sea, pp.163,185-200.

[2] Arya, C. and Wood, L. (1995). The relevance of cracking in concrete to corrosion of reinforcement. Concrete Society Technical report (44).

[3] Beeby, A. (1983). Cracking, cover and corrosion of reinforcement. Concrete International, 46(167), pp.35-40.

[4] Concrete structures standard. (2006). Wellington [N.Z.]: Standards New Zealand, pp.3-11,

[5] European Committee for standardization, (2004). British Standard Eurocode 2: Design of concrete structures. Part 1-1: General rules and rules for building. European Committee for standardization, pp.48-51.

[6] American Concrete Institute 318, (2004). Building Code Requirements for Structural Concrete and Commentary. American Concrete Institute, pp.83-85.

[7] Ministry of House and Urban-Rural Department of People's Republic of Chinese. (2009). Chinese code for durability design of concrete structures GB/T 50476-2008, China Construction Industry Press, 4(3), pp.16

[8] R, Saligar. (1936). High grade steel in reinforced concrete. Preliminary Publication, 2nd Congress, International Association for Bridge and Structural Engineering, pp.293-315.

[9] Beeby, A. (1978). Cracking and corrosion, Concrete in the Oceans. Technical ReportNo.1. Slough: Cement and Concrete Association.

[10] Broms, B. B. (1965) Crack Width and Crack Spacing in Reinforced Concrete Members. ACI Journal Proceedings, 62(10)

[11] Broms, B. B. (1965) Technique for Investigation of Internal Cracks in Reinforced Concrete Members. ACI Journal Proceedings, 62(1).

[12] Arya, C. and Wood. L (1995). The relevance of cracking in concrete to corrosion of reinforcement. Concrete Society Technical Report (44)

[13] H.A., Berman. (1972). Journal of Material, (7), pp.330.

[14] ASTM, G. (1990). Standard Test Method for Half- Cell Potentials of Uncoated Reinforcing Steel in Concrete. ASTM, pp.429-433. 